\title{
"O COMPLÔ DA TORCIDA": FUTEBOL E PERFORMANCE MASCULINA EM BARES
}

\author{
Édison Gastaldo \\ Universidade do Vale do Rio dos Sinos - Brasil
}

Resumo: Este artigo busca discutir aspectos da interação social ocorrente em bares onde são transmitidas partidas de futebol, em particular aqueles relacionados a performances de gênero. Os dados analisados referem-se a pesquisa etnográfica em curso desde o início de 2004, em bares da região metropolitana de Porto Alegre. São destacadas três modalidades performáticas ocorrentes no setting pesquisado: a presença no bar, os desafios verbais entre participantes e a teatralização jocosa. Considero que esses elementos - entre outros - revelam aspectos do complexo campo de significados relativos à masculinidade em nossa sociedade, compondo parte do fenômeno a que denomino "relações jocosas futebolísticas".

Palavras-chave: futebol, gênero, masculinidade, performance.

Abstract: This paper issues some topics of the social interaction occurrant in bars where football matches are transmitted, particularly aspects of gender performance. The data analysed refer to an ethnographic fieldwork being held since the beginning of 2004 in bars of the Greater Porto Alegre area, in Brazil. Three performatic modalities are discussed: the presence on the setting as performance, verbal challenges between the participants and joking dramatizations. I consider that these elements - among others - reveal part of the complex field of meanings related to masculinity in Brazilian society, being a constitutive part of the phenomenon that I call "football joking relationships".

Keywords: football (soccer), gender, masculinity, performance.

Desde o início dos anos 1980, com a publicação do hoje clássico Universo do Futebol, coletânea organizada por Roberto da Matta (1982), o complexo mundo do futebol passou a fazer parte do repertório temático da antropologia brasileira, superando décadas em que a pecha de “ópio do povo” resolvia su- 
mariamente a questão sobre esse esporte e sua apropriação pela cultura brasileira nas ciências sociais. Passados mais de 20 anos, o universo do futebol continua mostrando-se um campo fértil de possibilidades de pesquisa sobre a cultura brasileira contemporânea, com um bom volume de publicações em várias áreas do conhecimento. ${ }^{1}$

Neste artigo, proponho discutir alguns elementos da performatividade masculina característicos da situação de campo na qual tenho trabalhado desde o início de 2004, na pesquisa Arquibancada Eletrônica: Sociabilidade, Recepção e Gênero no Futebol Mediatizado, realizada no Programa de PósGraduação em Ciências Sociais Aplicadas da Universidade do Vale do Rio dos Sinos, com o apoio da Fapergs. A pesquisa, em breves linhas, consiste numa investigação etnográfica no contexto de bares onde são transmitidas partidas de futebol televisionado, buscando interpretar as lógicas relacionadas ao compartilhar coletivo do acesso ao mesmo produto de mídia - o jogo de futebol nesses ambientes de freqüência predominantemente masculina.

Após uma breve revisão sobre futebol, sociabilidade e performance de gênero no Brasil e algumas considerações sobre método, apresento três aspectos recorrentes de performatividade no contexto pesquisado: a presença no setting como performance, os desafios verbais entre participantes e a teatralização jocosa ali ocorrente, enquadrando estes aspectos no fenômeno mais abrangente a que denomino "relações jocosas futebolísticas".

\section{Futebol, sociabilidade e performance masculina no Brasil}

A noção de sociabilidade deriva da obra do sociólogo e filósofo alemão Georg Simmel, que a definiu como "a forma lúdica da sociação” (Simmel, 1983, p. 168). Para Simmel, a sociabilidade é uma forma de interação na qual os participantes se mostram a um só tempo interessados e descomprometidos, autonomizando suas atuações no sentido de evitar qualquer demonstração de um interesse objetivo nos assuntos tratados - o tipo de conversa ocorrente em festas

\footnotetext{
1 Como bons exemplos, eu destacaria o trabalho de Stigger (2002) no campo da educação física, o de Helal et al. (2001) na comunicação, Mascarenhas (2001) na geografia, além da vasta e qualificada produção sobre futebol na antropologia brasileira e latino-americana, como Guedes (1998), Damo (2002), Alabarces (2000), Archetti (2003) e muitos outros.
} 
seria talvez um bom exemplo. Nesse sentido, pode-se cotejar a noção de sociabilidade de Simmel à definição de “jogo” apresentada por Huizinga (1971, p. 33),

[...] o jogo é uma atividade ou ocupação voluntária, exercida dentro de certos e determinados limites de tempo e de espaço, segundo regras livremente consentidas, mas absolutamente obrigatórias, dotado de um fim em si mesmo, acompanhado de um sentimento de tensão e de alegria e de uma consciência de ser diferente da "vida cotidiana".

Evidentemente, as duas noções não se equivalem nos mínimos detalhes, mas, guardadas as diferenças, um paralelo entre elas permite pensar a sociabilidade como uma espécie de "jogo da vida social”, um momento lúdico (é bom lembrar a etimologia deste termo, derivado do latim ludus, “jogo”), de prazer, distinto das coisas "sérias" da vida cotidiana, este frágil refúgio das agruras do mundo do trabalho, da economia e da política. Não pretendo aqui discutir se a sociabilidade é subsumida à noção de jogo ou o contrário. Importa é destacar esses fenômenos no enquadre similar que estabelecem na vida cotidiana, no "campo finito de significação” (Schutz, 1962) que estipulam. O fenômeno específico que pretendo discutir refere-se a uma combinação complexa entre mídia, jogo, sociabilidade e performance: a sociabilidade estabelecida em torno do consumo coletivo de jogos de futebol e a tematização dos fatos do jogo em interações sociais cotidianas, evidenciadas em performances ocorrentes nos locais pesquisados.

Pelas características dessa modalidade de interação - pelo menos no caso brasileiro -, um novo termo pode ser adscrito a essa problemática: o papel de gênero masculino. Embora tenha havido nos últimos anos um notável crescimento da participação feminina no universo futebolístico (manifesto não só na audiência midiática e nos estádios, mas mesmo dentro de campo, como no sucesso internacional conquistado pela seleção brasileira de futebol feminino), o mundo do futebol no Brasil continua ainda a ser hegemonicamente um território masculino.

Tradicionalmente, a participação em jogos, competições e desafios é um traço característico do papel de gênero masculino nas mais diversas culturas. Desde grupos tribais ao redor do mundo, em grupos rurais e em nossa sociedade urbana moderna, boa parte dos significados articulados ao "ser homem" se relaciona com aceitar os desafios propostos por outros homens. ${ }^{2}$ Eventualmen-

2 Para uma revisão deste tema, ver Gastaldo (1995, p. 117 ss). 
te, esses desafios tomam a forma direta da ofensa à honra, caso em que se mostra necessário o recurso à ação agonística em público. Outras vezes, demanda-se reação ao desafio ou provocação em níveis mais simbólicos, respostas verbais, ironias, sarcasmos, ofensas ou réplicas afiadas, “dar a última palavra”. O fenômeno que gostaria de analisar aqui diz respeito a um tipo especial de performance, seja em atitude, desafio ou teatralização, em que a regra é manter o bom humor, mesmo - e principalmente - na derrota, suportando com paciência ou, de preferência, com uma resposta afiada e engraçada, as alfinetadas dos oponentes. Essa sociabilidade marcadamente masculina lida com o que Carmen Rial denominou "homossociabilidade” (comunicação pessoal, em 27 dec. 1995), forma lúdica de interação entre participantes de um mesmo sexo, no caso, de homens. A sociabilidade entre homens pode por vezes derivar para formas bastante agressivas de interação - que trafegam no estreito limite do que possa ser chamado de "brincadeira", na modalidade de interação a que Radcliffe-Brown (1959) denominou "relações jocosas", ${ }^{3}$ definidas como

[...] uma peculiar combinação de amizade e antagonismo. O comportamento é tal que em qualquer outro contexto social ele expressaria e geraria hostilidade; mas tal atitude não é a sério e não deve ser levada a sério. Há uma pretensão de hostilidade e uma real amizade. Posto de outro modo, é uma relação de desrespeito consentido. (Radcliffe-Brown, 1959, p. 91, tradução minha).

A interação pautada pela mediação de um evento esportivo se presta de modo notável para essa forma de sociabilidade competitiva - que poderia ser denominada "relação jocosa futebolística”, de que a "flauta”, "gozeira” ou "sacanagem” interminável de parte a parte entre gremistas e colorados, cruzeirenses e atleticanos, flamenguistas, pós-de-arroz e vascaínos é um bom exemplo. Muito freqüentemente a relação jocosa toma uma forma teatral e performática, para evidenciar pública e humoradamente o alinhamento dos participantes à situação. Em um dos bares pesquisados, durante a partida final do campeonato gaúcho de 2004, entre Internacional e Ulbra, os limiares da sociabilidade ficaram bastante claros: um torcedor gremista, um senhor de seus 60

3 Em outro clássico artigo sobre o tema, As Relações Jocosas de Parentesco, Marcel Mauss (1979) dedica-se mais ao parentesco propriamente dito do que à jocosidade, embora enfatize o papel flexibilizador das relações sociais desempenhado por essa instituição.

Horizontes Antropológicos, Porto Alegre, ano 11, n. 24, p. 107-123, jul./dez. 2005 
anos, cercado de colorados, zombava abertamente dos quase 30 torcedores adversários sentados em torno dele quando a Ulbra abriu o placar. O Internacional empatou e, ao virar o marcador, um outro senhor - colorado - sentado à sua frente ergueu uma cadeira pelo encosto, ameaçando bater no gremista com um indisfarçável sorriso. O garçom repreendeu-o, ao que o torcedor comentou: “que é isso, meu, é só brincadeira!” De fato, no exato instante em que o árbitro apitava o final do jogo, dando o título ao Internacional, o gremista levantou-se da cadeira e, generosamente, estendeu a mão ao "adversário", felicitando-o. Com um sorriso de parte a parte e tapinhas nas costas, se despediram. Como em Radcliffe-Brown, contrapondo-se à pretensa hostilidade, uma real amizade.

Em termos interacionais, a sociabilidade masculina brasileira tem na tematização do esporte um porto seguro. Basta perguntar a um homem qualquer qual o seu time para começar uma conversa que pode se alongar indefinidamente, sem que em qualquer momento se corra o risco de uma indiscrição ou constrangimento, uma vez que - por passionais que sejam os torcedores - nada que afete o self está em questão. Alie-se a esse tema, envolvente sem ser comprometedor, o constante fluxo de informações decorrente da tematização jornalística das editorias de esportes e temos o assunto perfeito para a sociabilidade masculina no Brasil. Como um exemplo, basta pensar nas verdadeiras “novelas” envolvendo os boatos de compra e venda de jogadores, relatos clínicos detalhados da recuperação de craques lesionados e especulações sobre resultados e tabelas que são veiculadas diariamente em jornais de todo o país: a tal “falação esportiva”, contra a qual Umberto Eco (1984) bradava em vão, é a matéria-prima de interações de sociabilidade masculina por todo o país.

Assim, as performances masculinas ocorrentes nos ambientes pesquisados são uma manifestação interacional cotidiana de aspectos profundos da cultura masculina no Brasil, evidenciando lógicas simbólicas de pertencimento e exclusão que, mediadas pelo futebol, resolvem pela jocosidade tensões que em casos extremos poderiam conduzir a confrontos físicos e violência. É evidente que brigas entre torcedores ocorrem, embora eu acredite que estas sejam antes a exceção do que a regra. Há que se considerar aqui o papel da imprensa, sobrevalorizando o "espetáculo midiático" de uma guerra de torcidas, muito mais noticiável do que a gozação cotidiana sem conseqüências, "levada na esportiva”, mais freqüente, mas menos noticiável. Nos quatro settings pesquisados, em mais de um ano de trabalho de campo, não foi registrado nenhum evento de briga, salvo um único enfrentamento entre torcedores (ca- 
sualmente, do mesmo clube) que, nos termos dos participantes, "se empeitaram”, confronto dissolvido pelos outros participantes antes da situação chegar às vias de fato. Fica evidente pelos depoimentos dos informantes que o saber "levar na esportiva” a gozação do oponente é condição necessária para a participação nesse jogo.

Eventualmente, o ambiente dos estádios e seus arredores, com milhares de torcedores separados fisicamente em dois grupos antagônicos - com o acréscimo de tensão decorrente da presença das torcidas organizadas ${ }^{4}$ e sua fama , talvez ofereça condições para a emergência de situações de violência simbólica e física mais acentuadas do que no ambiente dos bares, onde muitas vezes o torcedor oponente está sentado na mesa ao lado, e onde relações pessoais com o estabelecimento comercial ${ }^{5}$ modulam esta violência no sentido de favorecer sua expressão sob a forma de jocosidade, ironia, gozação. Manifestações de uma tensão da mesma ordem, mas preferencialmente sub specie ludi.

\section{Sobre método}

A pesquisa da qual este texto é um resultado parcial foi iniciada em março de 2004, e trata da recepção de futebol midiatizado em locais públicos, nomeadamente bares da região metropolitana de Porto Alegre. A equipe é composta pelo coordenador e três assistentes de pesquisa. Cada um dos membros está, desde abril de 2004, empenhado em trabalho de campo etnográfico, cada um em um bar - sempre o mesmo para cada participante. Inicialmente, o contato com a situação de campo consistiu basicamente em observação participante e redação de um diário de campo etnográfico, sendo posteriormente realizadas entrevistas com participantes da situação. Semanalmente, a equipe se reúne para trocar os relatórios e discutir coletivamente a experiência etnográfica. Assim, isolando um aspecto - a natureza estruturante de uma situação de campo similar, embora ocorrente em settings distintos - torna-se possível ampliar consideravelmente o campo de possibilidades interpretativas do fenômeno analisado, visando a lidar com um tradicional dilema da técnica

\footnotetext{
Sobre torcidas organizadas e violência nos estádios, ver Pimenta (1997) e Toledo (1996).

5 Valem aqui as regras do "pedaço", descritas por Magnani (1986): o custo pessoal e social de provocar uma briga no pedaço é bastante alto, e, como nos bares pesquisados por ele, a culpa por eventos desse tipo é normalmente imputada aos "de fora".
}

Horizontes Antropológicos, Porto Alegre, ano 11, n. 24, p. 107-123, jul./dez. 2005 
etnográfica: a dificuldade de fazer comparações entre situações de campo distintas, uma vez que cada situação é única em suas especificidades, mas pode ser pensada como parte de um fenômeno mais geral. ${ }^{6}$ De modo a ampliar a leitura de cada situação de campo específica, os componentes do grupo de pesquisa fazem também saídas no campo de cada um dos outros, de modo a facilitar tanto a leitura dos relatórios dos demais componentes quanto aprofundar a própria compreensão do fenômeno analisado como categoria geral. É evidente que a natureza do fenômeno pesquisado facilita essa troca de experiências. Um dos principais problemas enfrentados por qualquer etnógrafo - a negociação da sua entrada na situação de campo como observador participante $^{7}$ - já está de antemão resolvido: sendo os jogos transmitidos nos bares um evento público, não existe nenhuma barreira à participação dos pesquisadores, nenhum "papel social” a ser negociado, nenhuma "senha” a ser conquistada, já que a fluidez da situação e relativa indistinção dos participantes permitem acesso praticamente irrestrito. Senha, se há, é a “obrigação” tácita de pedir uma bebida tão logo se ocupe uma mesa.

Problema similar também é enfrentado pelos pesquisadores de recepção de mídia em ambiente doméstico, que se vêem freqüentemente no dilema de destruir com sua presença a naturalidade da situação pesquisada, tendo que conquistar o acesso e a confiança dos pesquisados a duras penas, ou então tendo que optar pela criação de uma situação artificial de "experimento", expondo pessoas a produtos de mídia em ambientes exteriores ao da recepção natural, procedimento que, para usar a expressão de Harold Garfinkel (1967), “perde o fenômeno”, uma vez que a situação pesquisada não é mais a situação natural de ocorrência, mas uma situação artificial, sui generis, e que, sujeita ao controle do pesquisador - que decide o que, para quem, quando e quantas vezes veicular - pouco diz do mundo da vida de que o contexto de recepção midiática é parte.

\section{Performance masculina nos bares: três modalidades}

O “campo finito de significação” suscitado pela transmissão de uma partida de futebol no ambiente dos bares é um fenômeno que dura aproximada-

\footnotetext{
${ }^{6}$ Sobre a questão das inferências no trabalho de campo, ver Becker (1998).

7 Para uma boa discussão sobre dificuldades metodológicas na etnografia, ver Cardoso (1986).
} 
mente duas horas. Pouco antes de começar o jogo, os bares estão em geral com apenas alguns freqüentadores, e várias mesas vazias. À medida que se aproxima o início do jogo, começam a chegar os torcedores, o pico de público ocorrendo por volta da metade do primeiro tempo, público que permanece praticamente inalterado até o final da partida. $\mathrm{O}$ número de torcedores varia entre um mínimo de 40 até mais de cem em dias de jogos importantes. A dinâmica de organização do espaço também muda durante o jogo. Normalmente, a organização das pessoas no espaço do bar se dá em torno das mesas. Cada conjunto de mesa, cadeiras e pessoas compõe uma unidade interacional mínima nesse contexto, que, conservando relativa autonomia das outras mesas, agrupam pessoas previamente conhecidas, que conversam entre si, voltadas umas para as outras em torno de cada mesa, permitindo categorizar o padrão do bar como um todo como "interação desfocada” (Goffman, 1963), isto é, quando as pessoas em co-presença física imediata em um dado ambiente não se alinham a uma mesma situação, mas em várias minissituações co-ocorrentes. Durante o jogo, essa lógica de organização do espaço é alterada; os torcedores voltam-se todos para o televisor (para tanto, muitos torcedores dão as costas para suas mesas, tornadas meros "porta-copos”), estabelecendo um "cone” cujo vértice é ocupado pelo aparelho de TV, configurando no ambiente uma "interação focada”, isto é, em que os diferentes participantes em co-presença imediata compartilham um alinhamento coletivo a uma mesma situação. Nessa nova organização do espaço, muda também a organização das conversas. Se no arranjo original o som do bar é de um ruído de vozes indistintas - somatório das conversas nas mesas -, durante o jogo ouve-se nitidamente o som do televisor, e, apesar de ainda haver conversas laterais, evidencia-se uma forma peculiar de enunciação: falam-se frases em voz alta, para o bar, para todos, sem olhar para os interlocutores, em geral a propósito de um fato do jogo - impedimento, falta, gol, etc. - ou a uma imagem exibida pela transmissão do evento ou sua narração. ${ }^{8}$ Assim, nesse contexto de imagens midiáticas, torcidas, jogos, ironias, provocações e desafios é que destaco três aspectos da intensa performatividade ali exibida: a própria presença neste setting como atitude, os desafios verbais e a teatralização jocosa.

8 Sobre aspectos narrativos presentes na locução esportiva, ver Gastaldo (2000). 


\section{Presenca como performance}

Estando no setting, todos os participantes são automaticamente adscritos a uma mesma categoria - torcedor - organizados em dois grupos opostos: "gremistas" ou "colorados". ${ }^{9}$ Boa parte dos torcedores manifesta seu pertencimento com roupas ou acessórios - em geral camisetas do clube, mas também bonés, abrigos ou outras peças. Entre os demais, vestidos com roupas normais, é possível estabelecer o alinhamento de cada torcedor pela simples observação de sua performance corporal relativa aos fatos do jogo. Uma vez que se toma como regra tácita que "quem não é gremista é colorado", e viceversa, o interesse de todos os torcedores se coloca alinhado invariavelmente com relação ao "outro", ou melhor, "contra” o outro. Torce-se tanto para o seu time quanto - talvez mesmo mais - contra o time rival. Pouco importa quem esteja jogando, cada partida é reinterpretada pelos códigos da rivalidade clubística local e rapidamente se sabe de que lado se está. ${ }^{10}$ Assim, há na situação um constante monitoramento entre os participantes visando a uma identificação de cada torcedor a um clube. Não poucas vezes fui interpelado por outros torcedores, sentados próximos, em voz baixa, numa verificação direta desse alinhamento: “Tu é colorado?" Com a resposta positiva, começa o diálogo sobre o jogo, em volume consideravelmente mais alto: "Pô, e esse nosso time, hein?" Com um pouco de paciência, e observando atentamente a reação dos presentes aos fatos do jogo - gols, pênaltis, faltas, boas jogadas, etc. - rapidamente se consegue um mapa dos alinhamentos dos torcedores na situação. Quando mais não seja, um gol - para qualquer time - é revelador instantâneo dos alinhamentos de todos.

Assim, estar no bar é ser considerado torcedor, e os torcedores são gremistas ou colorados. Ser torcedor é estar sujeito aos fatos do jogo, é colocar-se pessoalmente em jogo. No bar, ninguém escapa incólume de uma gole-

9 Evidentemente, no campo etnográfico em exame. Não obstante, à exceção de Rio de Janeiro e São Paulo, em que há mais de dois grandes grupos de torcedores, a dualidade futebolística é um padrão de organização das relações de torcedores largamente difundido no Brasil. Nesse sentido, ver Damo (2002).

${ }^{10}$ Em meados de 2004, jogavam São Paulo e Grêmio: a um gol do São Paulo, houve grande comemoração dos colorados. Ao comentário do locutor de que a vitória são-paulina seria ruim para o Inter na tabela, um torcedor retrucou: "Que, ruim o quê? O Grêmio que se foda!", reiterando publicamente a rivalidade local - pensada como mais importante do que a posição do próprio time no campeonato.

Horizontes Antropológicos, Porto Alegre, ano 11, n. 24, p. 107-123, jul./dez. 2005 
ada sofrida por seu time, a chacota dos oponentes é instantânea e infalível mesmo se o próprio time não estiver jogando, sempre há torcedores adversários - "secadores" - de prontidão. Que, uma vez identificados, podem ser alvo das mesmas chacotas num outro dia, quando os resultados forem desfavoráveis para eles, em uma lógica de implacável reciprocidade. Ou seja, o simples estar presente no "complô da torcida" - termo pelo qual um informante definiu o ambiente do bar-implica risco, o risco de ser zombado, um risco que independe dos torcedores, mas dos caprichos da bola e dos pés que a tangem. Ao risco da zombaria corresponde na mesma medida o prazer de zombar, o gosto da desforra de ancestrais gozações, seja de jogos e campeonatos ocorridos há muitos anos ou da semana passada, uma lógica identitária construída na oposição ao outro e na fidelidade ao clube, qualquer que seja o resultado. Lógica do jogo.

O valor atribuído à atitude implicada na simples presença nesse ambiente de risco ficou evidente há pouco tempo, quando o Internacional disputou a final do campeonato gaúcho de 2005 com o 15 de Novembro de Campo Bom. O jogo foi disputadíssimo, e muito tenso: na prorrogação, em seis minutos, o título mudou de dono quatro vezes, terminando com vitória do Internacional. Após o jogo, com os torcedores já deixando o bar, passou na rua em frente um carro com três rapazes buzinando, exibindo uma camiseta do Inter. Um torcedor colorado que estivera no bar o jogo inteiro comentou em voz alta, para quem quisesse ouvir: "Estavam tudo em casa com medo, agora que acabou, saíram, seus fiadasputa!” Manifesta-se aqui uma hierarquização entre os torcedores do mesmo clube, em que a não-presença no setting é denunciada como índice de "medo", ressaltando a "coragem" de quem se expôs ao risco, ${ }^{11}$ bem como a dicotomia entre "casa" - lugar de proteção, lugar feminino, nessa lógica - e "rua”, entendida como arena pública, lugar de correr riscos, lugar de homens, lógica masculina.

\section{Desafios verbais}

Como já foi visto, o ambiente dos bares durante um jogo é palco de uma modalidade muito peculiar de enunciação, que denomino "falar para todos”.

\footnotetext{
${ }^{11}$ Para Goffman (1967), a “emoção” suscitada por um evento está diretamente relacionada à dimensão do risco que se assume. Nos bares pesquisados, é freqüente o sublinhar de uma discussão com uma aposta em dinheiro, aumentando assim o risco associado à posição de cada participante.
}

Horizontes Antropológicos, Porto Alegre, ano 11, n. 24, p. 107-123, jul./dez. 2005 
Durante um jogo, essa modalidade de interação verbal se destaca, tanto pelo alto volume de voz com que as frases - curtas e mordazes - são proferidas, quanto pelo senso de humor que constantemente veiculam, bem como sua vinculação às imagens e definições da situação propostas pela transmissão de TV. O mais das vezes, esses comentários dizem respeito aos fatos do jogo propriamente ditos. Entretanto, como diversos estudos evidenciam, ${ }^{12}$ a transmissão de uma partida de futebol pela televisão não é exatamente o mesmo que o jogo: trata-se de um produto de mídia, com suas regras e codificações narrativas próprias, o que inclui mostrar imagens, ângulos, replays e detalhes alheios ao jogo, e aos quais os torcedores reagem, conforme a situação. Da mesma maneira, a locução, embora se pretenda "jornalisticamente fiel” aos fatos do jogo, é, ela também, matizada pelas convenções narrativas do veículo - rádio ou TV - evidenciando antes uma definição da situação proposta pelo locutor do que uma improvável e transparente evidência - embora discursivamente se proponha como tal. Assim, o "falar pra todos” é também uma modalidade de reação ao discurso midiático, perante as dezenas de torcedores presentes. Ordinariamente, essas enunciações têm intenção satírica, de uma aguda ironia, e às vezes suscitam gargalhadas no bar - dos companheiros e dos adversários. Na partida final do campeonato gaúcho de 2005, o Internacional venceu na prorrogação com dois gols de Souza, jogador execrado pelos torcedores, um centroavante que, até aquele momento do ano, tinha marcado um único gol, e não participava sequer do time principal. Na comemoração do segundo - e inesperado - gol, os torcedores gritaram, em coro: "ão, ão, ão, Souza é seleção!”, ironizando a própria descrença na inusitada situação.

Como um exemplo dessa modalidade de interação relativa às imagens transmitidas, eu destacaria o invariável reparo feito pelos torcedores à figura do então técnico do Internacional, o carioca Joel Santana, que, a cada aparição esporádica nas imagens do jogo recebia uma série de interpelações jocosas, aludindo a seu suposto alcoolismo: “Aí, Cachaça!” ou "Fala, Bob Esponja!” Nesse caso, o mote da sátira refere-se à perda do controle de si pelo alcoolista. Na medida em que a autonomia é um valor importante nessa lógica da identidade masculina, o consumo reiterado de bebidas alcoólicas é também, ele próprio, um desafio, o de "garantir a si mesmo", de não depender de ninguém. Uma

${ }^{12}$ Ver, nesse sentido, Gastaldo (2000) e Rial (2003), por exemplo. 
pessoa embriagada, que dependa de outra para caminhar ou para chegar em casa, nessa perspectiva, descredita-se a um pleno desempenho do papel masculino. Outro motivo de chacotas foi o ex-goleiro do Grêmio, Danrlei, então reserva no Atlético Mineiro, que apareceu de relance em uma imagem dos jogadores no banco e suscitou o comentário público: "Olha ali a bichona... Pena que daqui não dá pra jogar um radinho de pilha nele!” Aqui se evidencia outro mote perene dessa modalidade de sociabilidade masculina: a desqualificação do outro sob a "acusação" de homossexualidade, reiterando o aspecto da construção da identidade masculina denunciado por Chodorow (1979) como "repressão e desvalorização da feminilidade", que, ao atribuir atitudes "femininas" a um homem, o desqualifica perante os outros homens, a chamada "homofobia".

Com bastante freqüência, essas ações verbais, em forma de provocação à torcida adversária - ditas para todos - ensejam uma réplica no mesmo tom, instantânea e mordaz, configurando uma modalidade interacional de "desafio verbal”. A interação entre os participantes nesses casos toma a forma de um "par adjacente" (para usar um termo da Análise da Conversa), em que a uma chacota corresponde uma réplica instantânea de um participante da torcida oposta, que aceita e devolve o desafio. Como exemplo, pode ser referido um jogo em que o time do Grêmio entrava em campo, quando um torcedor gremista falou para todos: “Tá entrando o bicampeão da América!” A réplica foi imediata: “Tá entrando a segundona!” A paráfrase irônica alude ao recente rebaixamento da equipe do Grêmio à segunda divisão do campeonato brasileiro, enquanto o enquadre do torcedor gremista aludia a grandes títulos da história do clube: diferentes predicados articulados a uma mesma categoria, manejados como dardos. Igualmente, à crítica pública de um torcedor gremista ao mau desempenho de um de seus jogadores - "Tira esse homem de campo, pelamordedeus!!!” - justapõe-se instantaneamente o apelo zombeteiro do rival, em tom de campanha: "Fica, Marcelinho!"

Em outra ocasião, passou pelo bar um menino com uma bandeira vermelha, sem nenhum símbolo, somente a cor lisa. Um torcedor falou: "Que é isso, agora? Movimento dos Sem-Terra?” E a réplica: “É melhor Movimento dos Sem-Terra que Movimento dos Sem-Time, que vem de bandeira azul!!!” Às vezes, aguarda-se o momento certo para "dar o troco". Em um dos bares pesquisados, há dois televisores, um para o jogo do Inter e outro para o Grêmio; em uma falta grave contra um jogador do Grêmio, um torcedor exclamou: “Tem que expulsar!” A réplica veio, instantânea: “Que é isso, nem quebrou a perna! 
Futebol é pra homem...” Poucos minutos depois, no outro televisor, a uma falta igualmente grave contra um jogador do Inter, o mesmo torcedor que replicara gritou: “Tem que dar vermelho!” Veio o troco, zombeteiro e inevitável: “Ué, mas o senhor não falou que futebol é pra homem?”

\section{Teatralizaç̃o jocosa}

Por vezes, a performance zombeteira ultrapassa o limite do ato de fala, da tirada espirituosa ou da provocação com palavras. Nesses casos, os torcedores preparam e ensaiam previamente performances francamente humorísticas, que arrancam gargalhadas mesmo dos oponentes, seja com trocadilhos preparados de antemão ou adereços trazidos a público com finalidade jocosa. Trata-se do mesmo mote interacional dos desafios verbais, mas que evidenciam mais cuidado na elaboração e uma intencionalidade evidente de investir na promoção da interação jocosa, como colocar acintosamente um ventilador ligado em frente ao televisor para "secar" o jogo decisivo do time adversário.

No dia em que jogavam Grêmio versus Brasil de Pelotas, o Grêmio vencia por 1 a 0 , quando o Brasil marcou um gol de empate. Um torcedor colorado levantou-se, perfilado em posição de sentido, pôs a mão no coração e pôs-se a cantar a plenos pulmões: "Eu te amo, meu Brasil, eu te amo, meu coração é verde, amarelo, branco e azul anil!” A ressemantização da popular canção de propaganda da ditadura militar no início dos anos 1970 foi surpreendente e engraçada, e não teve outra réplica do que as gargalhadas do bar inteiro.

Na final do campeonato gaúcho de 2005, entre Inter e 15 de Novembro, o gerente do bar - gremista, pois no bar ninguém escapa à categorização por time - trouxe uma vela grossa e bastante derretida e mostrou-a a todo o bar, dizendo que era uma "macumba pro Inter". Leva a vela até um cadeirão de criança no canto do bar e a acende. Pouco depois, o goleiro colorado fratura o braço e sai de ambulância. O gerente olha em torno, com ar zombeteiro, capturando o olhar dos torcedores, em seguida olha pra vela e mexe os dedos das duas mãos com os braços estendidos em direção a ela, gesto de bruxaria. Sem o goleiro, o Inter leva 1 a 0. O 15 passa a levar o jogo para a prorrogação. Um torcedor gremista fala: "É a velinha!” Um torcedor colorado vai sorrateiramente até a vela e a apaga. O gerente finge indignação, e torna a acendê-la. No final do jogo, ele apaga a vela, dizendo a todos que ia "guardar pra prorrogação”. Na prorrogação, com o desfecho do campeonato ocorrendo nos últimos

Horizontes Antropológicos, Porto Alegre, ano 11, n. 24, p. 107-123, jul./dez. 2005 
minutos, o gerente põe a culpa na vela, que teria acabado antes da hora. Um ano antes, na final do campeonato gaúcho de 2004, um torcedor colorado trouxe uma faixa em que se lia: “Eu já sabia!” Entretanto, o jogo começou com o Inter levando 1 a 0 da Ulbra, ao que o torcedor levantou sua faixa para todo o bar, porém de cabeça pra baixo. “Opa!”, disse ele, fingindo ter-se enganado. No final, com a vitória, a faixa pôde cumprir sua "função". Quando o gerente foi cumprimentá-lo pelo campeonato, o torcedor pegou-o pelo pescoço, simulando uma "gravata", e passou o punho fechado pela sua cabeça, descabelandoo, em uma pretensa hostilidade, da qual se apartaram entre gargalhadas.

\section{Para concluir}

O universo simbólico do futebol na cultura brasileira mostra-se como um território de expressão de importantes aspectos dessa cultura, constituindo-se por vezes como uma espécie de "fato social total” em nossa sociedade. ${ }^{13} \mathrm{~A}$ pesquisa etnográfica do contexto de recepção coletiva de jogos de futebol em bares, dessa maneira, evidencia, através das performances dos participantes na situação, aspectos profundos do ethos masculino no Brasil. A disposição de assumir riscos, considerada como valor social masculino, manifesta-se na valorização da simples presença na situação, uma vez que, estando lá, automaticamente se é imputado um papel social, o de torcedor, e um "lado" em um sistema de mútua exclusão - gremista e anticolorado ou colorado e antigremista. A partir desta adscrição tácita de um lugar na situação, “estar lá” implica correr riscos, colocar-se em jogo: ser gozado ou gozador depende não da vontade dos torcedores, mas do imponderável resultado em campo, o que faz do ir ao bar um empreendimento com alto grau de incerteza. Como Goffman (1967) comenta em Where the Action Is, a emoção atribuída a uma situação é dependente do quanto se está arriscando. Reitera esse motivo a notável freqüência com que se propõem apostas em dinheiro associadas ao desfecho dos jogos ou a eventos dentro deles, como o resultado de uma cobrança de pênalti, por exemplo.

Essa lógica masculina competitiva assume também a forma de desafios verbais, um outro “jogo” dentro do jogo, relações jocosas futebolísticas em

\footnotetext{
${ }^{13}$ Por exemplo, em jogos da seleção brasileira na Copa do Mundo. Sobre esse tema, ver Gastaldo (2002).
} 
estado puro, na arena pública, na frente de todos. É interessante notar que, como o pertencimento clubístico nesse contexto opera como único fator válido na definição da situação pelos participantes, não chega a haver ameaças ao self de nenhum dos participantes, salvo o eventual extremo a que um dado participante leve a gozação aos oponentes: provavelmente, na hora em que os pratos da balança se inverterem, ele será um alvo preferencial. Mas, novamente, é na condição de colorado ou gremista “doente” que ele será interpelado, e não por qualquer outro atributo pessoal - que, se fosse enquadrado como "desaforo” ou “ofensa”, demandaria reparação da honra ameaçada: violência física. ${ }^{14}$

Assim, considero importante destacar que o universo simbólico do futebol supera largamente os fatos sociais ocorridos nos estádios, no campo e nas arquibancadas, mas que se espraia pelas páginas dos jornais todos os dias, que ocupa horas de programação e canais inteiros de rádio e televisão e - muito além dos 90 minutos do jogo - manifesta-se nas interações sociais cotidianas, na sociabilidade descomprometida que, alinhando o "outro” - qualquer outro a um dos “lados”, oferece possibilidade de interação, solidária ou jocosa, amenizando a dureza das relações “sérias”, profissionais, legais ou familiares: fenômeno instigante e que demanda compreensão.

\section{Referências}

ALABARCES, P. (Org.). Peligro de gol: estudios sobre deporte y sociedad en América Latina. Buenos Aires: Clacso, 2000.

ARCHETTI, E. Masculinidades: fútbol, tango y polo en la Argentina. Buenos Aires: Antropofagia, 2003.

BECKER, H. S. Métodos de pesquisa em ciências sociais. São Paulo: Hucitec, 1998.

CARDOSO, R. C. L. (Org.). A aventura antropológica. Rio de Janeiro: Paz e Terra, 1986.

\footnotetext{
${ }^{14}$ Reitero aqui que a combinação desses elementos de competitividade, jocosidade, dualismo absoluto e conflito flerta com a irrupção de violência, e que eventualmente esses limites possam ser de fato ultrapassados. Porém, a não ocorrência de eventos de violência física em quatro settings ao longo de mais de um ano de observação participante é um indicativo de que os mecanismos interacionais de regulação permitem aos participantes correr o risco e jogar com esse limite.
} 
CHODOROW, N. Estrutura familiar e personalidade feminina. In: ROSALDO, M.; LAMPHERE, L. (Org.). A mulher, a cultura, a sociedade. Rio de Janeiro: Paz e Terra, 1979. p. 254.

DA MATTA, R. (Org.). Universo do futebol. Rio de Janeiro: Pinakotheke, 1982.

DAMO, A. S. Futebol e identidade social: uma leitura antropológica das rivalidades entre torcedores e clubes. Porto Alegre: UFRGS, 2002.

ECO, U. A falação esportiva. In: ECO, U. Viagem na irrealidade cotidiana. Rio de Janeiro: Nova Fronteira, 1984. p. 220-226.

GARFINKEL, H. Studies in Ethnomethodology. New York: Prentice-Hall, 1967.

GASTALDO, E. Kickboxers: esportes de combate e identidade masculina. Dissertação (Mestrado em Antropologia Social)-PPGAS, Universidade Federal do Rio Grande do Sul, Porto Alegre, 1995.

GASTALDO, E. Os campeões do século: notas sobre a definição da realidade no futebol-espetáculo. Revista Brasileira de Ciências do Esporte, Campinas: Autores Associados/CBCE, v. 22, n. 1, p. 105-124., set. 2000.

GASTALDO, E. Pátria, chuteiras e propaganda: o brasileiro na publicidade da Copa do Mundo. São Paulo: Annablume; São Leopoldo: Unisinos, 2002.

GOFFMAN, E. Behavior in public places. New York: The Free Press, 1963. GOFFMAN, E. Interaction ritual. Garden City: Doubleday, 1967.

GUEDES, S. L. O Brasil no campo de futebol: estudos antropológicos sobre os significados do futebol brasileiro. Niterói: EdUFF, 1998.

HELAL, R. et al. A invenção do país do futebol: mídia, raça e idolatria. Rio de Janeiro: Mauad, 2001.

HUIZINGA, J. Homo ludens: o jogo como elemento da cultura. São Paulo: Perspectiva, 1971.

MAGNANI, J. G. C. Festa no pedaço: lazer e cultura popular na cidade. São Paulo: Brasiliense, 1986.

MASCARENHAS, G. A bola nas redes e o enredo do lugar: uma geografia do futebol e de seu advento no Rio Grande do Sul. Tese (Doutorado em Geografia)-FFLCH, Universidade de São Paulo, São Paulo, 2001.

MAUSS, M. As relações jocosas de parentesco. In: OLIVEIRA, R. C. (Org.). Antropologia. São Paulo: Ática, 1979. p. 164-176. 
PIMENTA, C. A. M. Torcidas organizadas de futebol: violência e autoafirmação, aspectos das novas relações sociais. Taubaté: Vogal, 1997.

RADCLIFFE-BROWN, A. R. Structure and function in primitive society. London: Cohen and West, 1959.

RIAL, C. Futebol e mídia: a retórica televisiva e suas implicações na identidade nacional, de gênero e religiosa. Antropolítica: Revista Contemporânea de Antropologia e Ciência Política, Niterói: UFF, v. 14, n. 2, p. 61-80, 2003.

SCHUTZ, A. Collected papers. Den Haag: Martinus Nijhoff, 1962.

SIMMEL, G. Sociabilidade: um estudo de sociologia pura ou formal. MORAES FILHO, E. (Org.). Sociologia. São Paulo: Ática, 1983. p. 165-181.

STIGGER, M. P. Esporte, lazer e estilo de vida: um estudo etnográfico. Campinas: Autores Associados, 2002.

TOLEDO, L. H. Torcidas organizadas de futebol. Campinas: Autores Associados: Anpocs, 1996. 